\title{
Decreased mitochondrial DNA content in blood samples of patients with stage I breast cancer
}

\author{
Peng Xia1,2, Han-Xiang An*3, Cheng-Xue Dang*1, Ramin Radpour ${ }^{2}$, \\ Corina Kohler ${ }^{2}$, Emmanouil Fokas ${ }^{3}$, Rita Engenhart-Cabillic ${ }^{3}$, \\ Wolfgang Holzgreve ${ }^{4}$ and Xiao Yan Zhong ${ }^{2}$
}

\begin{abstract}
Address: ${ }^{1}$ Department of Surgical Oncology, First Affiliated Hospital of Medical College, Xi'an Jiaotong University, 710061 Xi'an, PR China, ${ }^{2}$ Laboratory for Prenatal Medicine and Gynecological Oncology, Women's Hospital and Department of Biomedicine, University of Basel, Switzerland, ${ }^{3}$ Department of Radiotherapy and Radiation Oncology, Philipps-University Marburg, Baldingerstr. D-35043 Marburg, Germany and ${ }^{4}$ Medical Center, Abert-Ludwigs-University-Freiburg, Germany

Email: Peng Xia - xiapeng30000@yahoo.com.cn; Han-Xiang An* - an@med.uni-marburg.de; ChengXue Dang* - dangchengxue@yahoo.com.cn; Ramin Radpour - radpourr@uhbs.ch; Corina Kohler - kohlerc@uhbs.ch; Emmanouil Fokas - fokas@med.uni-marburg.de; Rita Engenhart-Cabillic - engenhar@med.uni-marburg.de; Wolfgang Holzgreve - wolfgang.holzgreve@uniklinik-freiburg.de; Xiao Yan Zhong -xzhong@uhbs.ch

* Corresponding authors
\end{abstract}

Published: 2I December 2009

BMC Cancer 2009, 9:454 doi:10.1 186/147/-2407-9-454

This article is available from: http://www.biomedcentral.com/I47I-2407/9/454

(c) 2009 Xia et al; licensee BioMed Central Ltd.

This is an Open Access article distributed under the terms of the Creative Commons Attribution License (http://creativecommons.org/licenses/by/2.0), which permits unrestricted use, distribution, and reproduction in any medium, provided the original work is properly cited.
Received: 19 November 2008

Accepted: 21 December 2009

\begin{abstract}
Background: Alterations of mitochondrial DNA (mtDNA) have been implicated in carcinogenesis. We developed an accurate multiplex quantitative real-time PCR for synchronized determination of mtDNA and nuclear DNA (nDNA). We sought to investigate whether mtDNA content in the peripheral blood of breast cancer patients is associated with clinical and pathological parameters.

Methods: Peripheral blood samples were collected from 60 patients with breast cancer and $5 \mathrm{I}$ agematched healthy individuals as control. DNA was extracted from peripheral blood for the quantification of mtDNA and nDNA, using a one-step multiplex real-time PCR. A FAM labeled MGB probe and primers were used to amplify the mtDNA sequence of the ATP 8 gene, and a VIC labeled MGB probe and primers were employed to amplify the glyceraldehyde-3-phosphate-dehydrogenase gene. mtDNA content was correlated with tumor stage, menstruation status, and age of patients as well as lymph node status and the expression of estrogen receptor (ER), progesterone receptor (PR) and Her-2/neu protein.

Results: The content of mtDNA in stage I breast cancer patients was significantly lower than in other stages (overall $P=0.023$ ). Reduced $m t D N A$ was found often in post menopausal cancer group $(P=0.024)$. No difference in mtDNA content, in regards to age $(p=0.564)$, lymph node involvement $(p=0.673)$, ER $(p=0.877)$, PR $(p=0.763)$, and Her-2/neu expression $(p=0.335)$, was observed.

Conclusion: Early detection of breast cancer has proved difficult and current detection methods are inadequate. In the present study, decreased mtDNA content in the peripheral blood of patients with breast cancer was strongly associated with stage I. The use of mtDNA may have diagnostic value and further studies are required to validate it as a potential biomarker for early detection of breast cancer.
\end{abstract}




\section{Background}

More than 75 years since Warburg described how tumor cells avidly consume glucose and produce lactic acid under aerobic conditions, it still remains unclear how this metabolic shift provides tumor cells with a growth advantage[1,2]. Recent evidence has shown that tumor cells adapt their metabolism to the microenvironment by suppressing mitochondrial function rather than increasing glycolysis [3]. In patients with mitochondrial disease, mitochondrial function is vulnerable to damages due to deletions, mutations or replication abnormalities of mitochondrial DNA (mtDNA) resulting in energy depletion and increased susceptibility to apoptosis [4]. Additionally, mtDNA alterations are correlated with various cancer types, suggesting that the mitochondrial genome may be a critical contributing factor in carcinogenesis. mtDNA content has been implicated as a potential biomarker for several cancer types [5]. Decreased mtDNA content had been reported for renal [6], gastric [7], breast [5,8], previously-treated head and neck [9], ovarian [10] and hepatic cancer [11-13]. In contrast, several studies have revealed an increased mtDNA content in prostate [14], untreated head and neck [15], thyroid [5], endometrial [16], and pancreatic cancer [17]. Interestingly, mtDNA alterations were also detected in bodily fluids, suggesting that mtDNA changes might serve as sensitive early biomarker for non-invasive detection of several types of solid cancer including breast cancer [18].

Similarly to previous reports [5], we have shown that mtDNA content was decreased in $82 \%$ of cancerous breast tissues, as compared with the normal ones[19]. However, to our best knowledge, no data exist regarding mtDNA content in peripheral blood of breast cancer patients and its correlation with clinical-pathological parameters. In the present study, we measured mtDNA content from peripheral blood samples of patients with breast cancer using a novel multiplex quantitative real-time PCR, as previously described [20]. The association between peripheral blood mtDNA content and clinical-and pathological parameters was analyzed and compared with the healthy donors.

\section{Methods \\ Sample collection}

Blood samples from 60 patients with breast cancer were taken before primary surgery. All patients were diagnosed between 2005 and 2007 and underwent surgery at the First Affiliated Hospital of Medical School of Xi'an Jiao Tong University of China. 51 control samples were randomly selected among individuals visiting hospitals for regular health checks. All patients gave informed consent for retention and analysis their blood for research purpose according to institutional guidelines and the study was approved by the research ethics committee of the Medical
School of Xi'an Jiao Tong University, China. Tumors were staged according to the TNM classification (Union Internationale Contre le Cancer, UICC). None of patients received neoadjuvant treatment or have distant metastases as the time of primary surgery. Hematoxylin and eosin staining was used for routine pathological evaluation. Expression of estrogen receptor (ER), progesterone receptor (PR) and Her-2/neu protein was determined by immunohistochemistry. Clinical-pathological data (age, histological grade, tumor size, lymph node status, ER-, PR-, and Her-2/neu expression) are summarized in Table 1. The median ages of the cancer and the control group were $49.5 \pm 1.6$ years and $51.0 \pm 2.0$ years, respectively.

\section{DNA isolation and multiplex quantitative real-time PCR}

DNA was subsequently isolated from whole blood by phenol-chloroform extraction and ethanol precipitation [21]. The DNA samples were divided into aliquots of 100 $\mu \mathrm{l}$ and were stored in $-80^{\circ} \mathrm{C}$. The ABI PRISM 7000 Sequence Detection System (Applied Biosystems, ABI) was used to amplify the GAPDH housekeeping gene and the mitochondrial DNA encoded ATPase (MTATP) 8 gene. Primers and probes used for detection of GAPDH and MTATP 8 gene sequences were: GAPDH (forward): 5'CCC CAC ACA CAT GCA CTT ACC; (reverse): 5'-CCT AGT CCC AGG GCT TTG ATT; probe 5'-(MGB)-TAG GAA GGA CAG GCA AC (VIC). Mitochondrial DNA (forward): 5'AAT ATT AAA CAC AAA CTA CCA CCT ACC; (reverse): 5'TGG TTC TCA GGG TTT GTT ATA; probe: 5'-(MGB)-CCT CAC CAA AGC CCA TA (FAM). The real-time RT-PCR was carried out in $25 \mu \mathrm{l}$ of total reaction volume containing 5 $\mu \mathrm{l}$ (40 ng) of DNA, $12.5 \mu \mathrm{l}$ of TaqMan ${ }^{\circledR}$ Universal PCR Master Mix, 4 primers and 2 probes using a 2 minute incubation at $50^{\circ} \mathrm{C}$, followed by an initial denature step at $95^{\circ} \mathrm{C}$ for 10 minutes and 40 cycles of 1 minute at $60^{\circ} \mathrm{C}$ and 15 seconds at $95^{\circ} \mathrm{C}$. All samples were analyzed in triplicate. To determine the quantities of mtDNA and nDNA present in blood samples, the average threshold cycle number $(\mathrm{Ct})$ values of the nDNA and mtDNA were obtained from each case. The level of mtDNA was calculated using the delta $\mathrm{Ct}(\Delta \mathrm{Ct})$ of average $\mathrm{Ct}$ of mtDNA and nDNA $(\Delta \mathrm{Ct}=\mathrm{CtmtDNA}-\mathrm{CtnDNA})$ in the same well as an exponent of $2\left(2^{\Delta \mathrm{Ct}}\right)$.

\section{Statistical analysis}

Contents of mtDNA and nDNA are given as the median, the range and the fold difference. Receiver operating characteristic (ROC) curves were generated to estimate the sensitivity and specificity of mtDNA content. The ShapiroWilk test was used to analyze the data distribution. It showed that our data set was not normally distributed ( $\mathrm{p}$ $=0.000$ and 0.010 for the mtDNA- and the GAPDH assay, respectively). The two-sample Kolmogorov-Smirnov (KS) test was used to compare the content of mtDNA in blood between the control- and breast cancer group. The 
Table I: Patient's data and correlation between levels of mtDNA in peripheral blood of patients with breast cancer and clinicalpathological parameters

\begin{tabular}{|c|c|c|c|}
\hline Variable & Number & $\begin{array}{l}\text { mtDNA content } \\
\text { Median (Range) }\end{array}$ & $P$ value \\
\hline \multicolumn{4}{|l|}{ Age (years) } \\
\hline$<50$ & 30 & $525.96(0.47-35241.80)$ & $* 0.564$ \\
\hline$\geq 50$ & 30 & $660.59(0.39-27175.14)$ & \\
\hline \multicolumn{4}{|c|}{ Menopausal status } \\
\hline pre & 37 & $1365.30(0.47-3524 \mid .80)$ & $* 0.024$ \\
\hline post & 23 & $262.29(0.39-5166.60)$ & \\
\hline \multicolumn{4}{|c|}{ Lymph-node status } \\
\hline negative & 29 & $668.60(4.23-27175.14)$ & $* 0.673$ \\
\hline positive & 31 & $436.55(0.39-35241.80)$ & \\
\hline \multicolumn{4}{|l|}{ Stage } \\
\hline 1 & 20 & $196.94(0.47-6841.04)$ & $* * 0.023$ \\
\hline II & 20 & $1656.18(10.89-35241.80)$ & \\
\hline III-IV & 20 & $572.71(0.39-4956.14)$ & \\
\hline \multicolumn{4}{|c|}{ (2) } \\
\hline positive & 29 & $657.11(0.39-35241.80)$ & $* 0.877$ \\
\hline negative & 31 & $376.11(0.47-27175.14)$ & \\
\hline \multicolumn{4}{|c|}{ (2) } \\
\hline positive & 36 & $654.85(4.23-27175.14)$ & $* 0.763$ \\
\hline negative & 24 & $669.09(0.39-35241.80)$ & \\
\hline \multicolumn{4}{|c|}{ Her2/neu protein } \\
\hline positive & 32 & $242.96(0.39-35241.80)$ & $* 0.335$ \\
\hline negative & 28 & $824.78(10.89-27175.14)$ & \\
\hline
\end{tabular}

*P values are obtained by using the Mann-Whitney $U$ test. ** $\mathrm{P}$ values are obtained by using one-way ANOVA on the rank followed by the Tukey test.

Spearman's rho analysis was applied to analyze the relationship of mtDNA content in peripheral blood between the two groups. The Mann-Whitney U Test and KruskalWallis test were employed to compare mtDNA content with clinical-pathological parameters in breast cancer group. We converted the mtDNA content values to ranks, and then did one-way ANOVA on the ranks in order to use the Tukey post-hoc procedure for the pairwise comparions of mtDNA content in relation to tumor stage. Differences were considered significant when $\mathrm{p}<0.05$. All statistical analyses were performed using the SPSS version 15.0 software (SPSS Inc., Chicago, IL).

\section{Results}

Measurements of the efficiency of multiplex Assays

The specificity of the assay for detecting the mtDNA was assessed using the mtDNA depleted 143b rho0cell line. No positive amplification of nucleus-embedded mtDNA sequences was obtained from the cell line using the assay for mtDNA (data not shown). To determine the quantities of mtDNA and nDNA present in blood samples, standard dilution curves were generated from a human genomic DNA with known concentrations, ranging from $3.125 \times$ $10^{4}$ to $10 \mathrm{pg} / \mu \mathrm{l}$ (including 31250, 6250, 1250, 250, 50 and $10 \mathrm{pg} / \mu \mathrm{l})$. We used experimental serial dilutions to examine the amplification efficiencies for the MTAPT-8gene amplicon (79 bp) for representing total mtDNA, and the GAPDH-gene amplicon ( $97 \mathrm{bp}$ ) for representing total
nDNA. The amplifications of mtDNA and nDNA on serial dilutions showed a good correlation with comparable efficiencies of close to $99 \%$.

\section{Co-extraction of mtDNA and nDNA from peripheral blood} samples of breast cancer patients

The average $\mathrm{Ct}$ values of GAPDH ranged from 20.16 to 24.71 in blood samples of patients with breast cancer and from 21.73 to 25.73 in whole blood samples of the control group, respectively. The average $\mathrm{Ct}$ values of MTATP 8 gene ranged from 10.65 to 21.54 in blood samples of patients with breast cancer and from 11.78 to 14.88 in whole blood samples of the control group, respectively. In breast cancer patients, mtDNA content was higher than nDNA (Table 2).

The average Ct values of GAPDH amplicon in the normal group were correlated with those of MTATP8 gene amplicon (Spearman's rho Test: $\mathrm{p}<0.001, \mathrm{r}=0.496$ ) (Figure 1 ). In contrast, no significant correlation was detected in cancerous group $(\mathrm{p}>0.05, \mathrm{r}=0.148$ ) (Figure 2$)$, suggesting an alteration of the relationship between nDNA and mtDNA in blood samples of breast cancer patients.

\section{mtDNA in whole blood samples from the normal and} breast cancer group

We used a formula of $2^{\Delta \mathrm{Ct}}$ to calculate the content of mtDNA in whole blood. The area under the ROC curve for 
Table 2: Level of mtDNA content in peripheral blood of the control- and breast cancer groups

\begin{tabular}{|c|c|c|c|c|}
\hline & $\begin{array}{c}\text { Normal } \\
\mathbf{N}=\mathbf{5 0}\end{array}$ & $\begin{array}{c}\text { Breast Cancer } \\
\mathbf{N}=60\end{array}$ & $\begin{array}{l}\text { Change } \\
(\Delta \Delta \mathrm{Ct})\end{array}$ & $P$ value \\
\hline \multicolumn{5}{|c|}{$\Delta \mathrm{Ct}\left(\mathrm{Ct}_{\mathrm{nDNA}}-\mathrm{Ct}_{\mathrm{mtDNA}}\right)$} \\
\hline Median & 10.43 & 9.36 & & \\
\hline Range & $6.07-12.03$ & $-|.37-| 5.1 \mid$ & 1.07 & \\
\hline \multicolumn{5}{|l|}{ mtDNA content } \\
\hline Median & 1374.79 & 654.85 & & $*_{p}=0.009$ \\
\hline Range & $66.95-4182.07$ & $0.39-35241.80$ & 2.10 & \\
\hline \multicolumn{5}{|l|}{ Correlation } \\
\hline$\left(C t_{n D N A}\right.$ vs $\left.C t_{m t D N A}\right)$ & $\begin{array}{c}r=0.496 \\
*_{p}=0.000\end{array}$ & $\begin{array}{c}r=0.148 \\
* * p=0.259\end{array}$ & & \\
\hline
\end{tabular}

* Kolmogorov-Smirnov (K-S) test; ** Spearman's rho test.

the mtDNA content was 0.76 (95\% confidence interval, $0.67-0.87$ ) with sensitivity of 73 and specificity of $78 \%$. A 10.43 cycle difference in normal group and a 9.36 cycle difference in cancerous group were found by calculating the $\Delta \mathrm{Ct}$ values between GAPDH amplicon and MTATP 8 gene amplicon. The $\Delta \mathrm{Ct}$ values between normal and cancerous group showed a 1.07 cycle difference $(\Delta \Delta \mathrm{Ct})(\mathrm{p}<$ 0.01 ) as shown in Table 2.

\section{Relationship between decreased content of mtDNA and clinical parameters}

mtDNA content was compared with various clinical and pathological parameters of breast cancer patients such as age, menopause, TNM stage, lymph node status, ER-, PR-

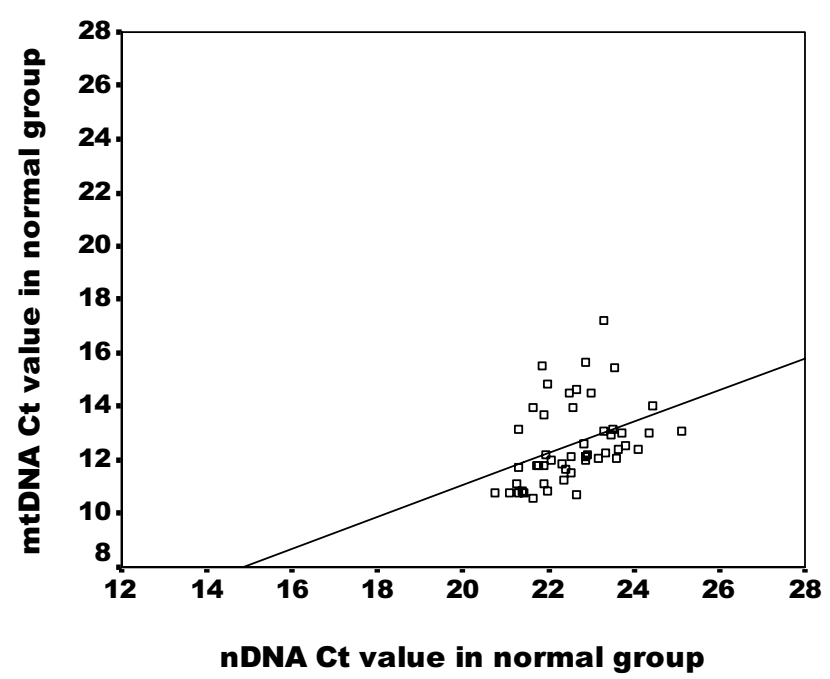

Figure I

Correlation of nDNA content and mtDNA content in peripheral blood in normal group. Scatter plot illustrates the $\mathrm{Ct}$ values of GAPDH amplicon ( $X$ axis) against the Ct values of MTATP 8 amplicon ( $Y$ axis) in blood samples of normal group $(n=50)$. The correlation rate is highly significant $(p=0.000 \mathrm{I})$ according the Spearman' rho test. and Her-2/neu expression (Table 1). No significant difference in mtDNA content of peripheral blood was observed in regards to age, lymph node involvement, ER-, PR- and Her-2/neu expression (Table 1). However, the mtDNA content was significantly lower in stage 2 than in the other stages (Table 1 and Figure 3 , overall $\mathrm{P}=0.023$, I vs II, $\mathrm{P}=$ $0.018)$. The decreased mtDNA content in breast cancer patients was also correlated to menopausal status of beast cancer patients (Table 3 and Figure 4, P =0.024). Significant decreased mtDNA content of peripheral blood was found in postmenopausal patients with cancer compared with that in postmenopausal normal group (Figure $4, \mathrm{P}=$ $0.019)$.

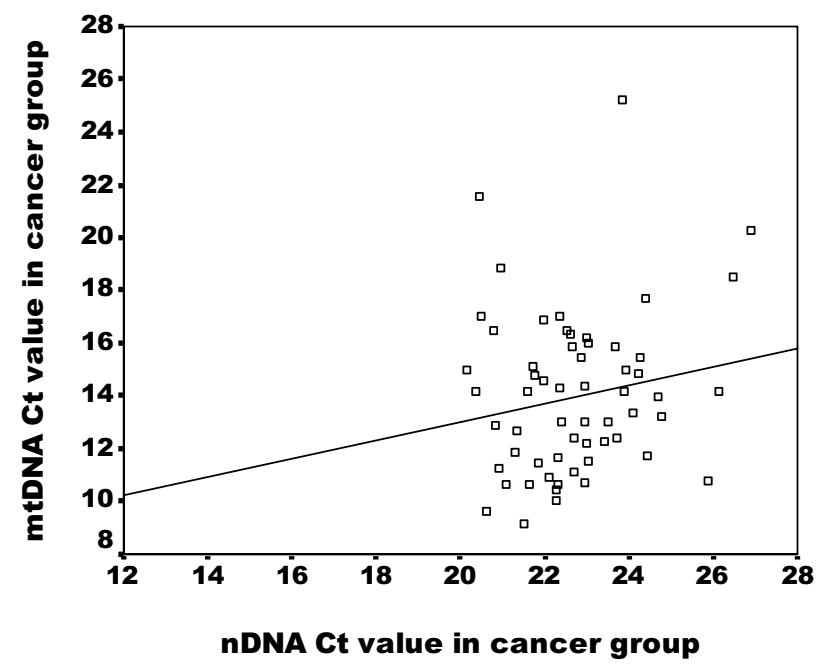

Figure 2

Correlation of $n$ DNA content and mtDNA content in peripheral blood in breast cancer group. Scatter plot illustrates the $\mathrm{C} t$ values of GAPDH amplicon ( $\mathrm{X}$ axis) against the $C t$ values of MTATP 8 amplicon ( $Y$ axis) in blood samples of breast cancer group $(n=60)$. The correlation rate is not significant $(p=0.259)$ according the Spearman' rho test. 
Table 3: The correlation between the menopausal status and the levels of mtDNA in peripheral blood of breast cancer and normal groups

\begin{tabular}{lccc}
\hline Variable & Number & $\begin{array}{c}\text { mtDNA content } \\
\text { Median (Range) }\end{array}$ & \\
\hline $\begin{array}{l}\text { Cancer } \\
\text { Menopausal status }\end{array}$ & & & \\
$\quad$ pre & 37 & $1365.30(0.47-35241.80)$ & 0.024 \\
$\quad$ post & 23 & $262.29(0.39-5166.60)$ & \\
$\begin{array}{l}\text { Normal } \\
\text { Menopausal status } \\
\text { pre } \\
\text { post }\end{array}$ & 31 & $1443.15(136.71-4182.07)$ & 0.396 \\
\hline
\end{tabular}

$P$ values are obtained by using the Mann-Whitney $U$ Test.

\section{Discussion}

mtDNA is vulnerable to DNA damage due to: a) the lack of protective histones; b) insufficient DNA repair capacity; c) a high rate of reactive oxygen species generation in mitochondria [22]. Mitochondria play an essential role in cellular energy metabolism, free radical generation and programmed cell death [23]. According to these characteristics and functions of mtDNA, it has been noted that alterations found in mtDNA could be involved at the early stage of carcinogenesis [24] and may play an important role in mitochondrial dysregulation and cancer develop-

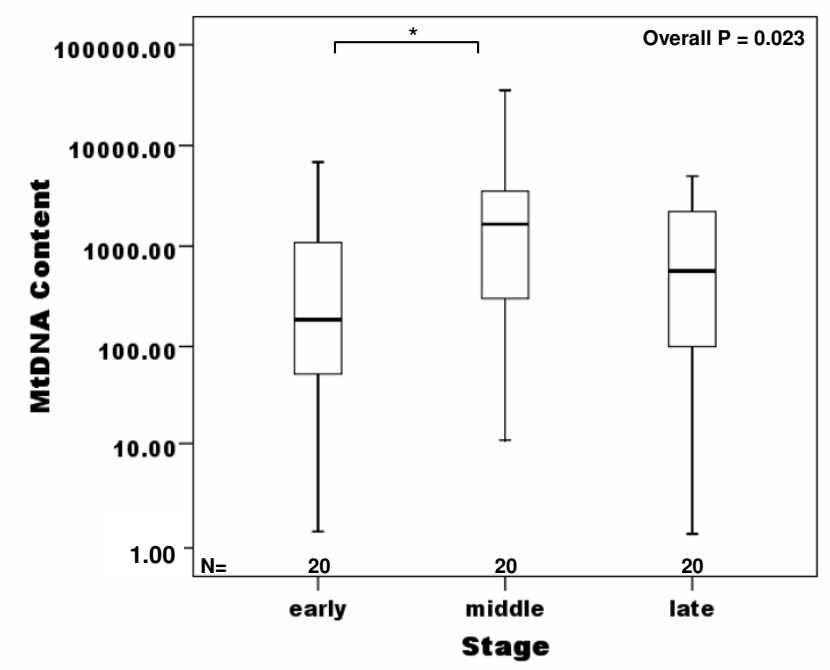

Figure 3

Box plot analysis illustrating levels of mtDNA in peripheral blood of normal group and breast cancer groups according the stage ofcarcinomas. The quantitative mtDNA content (as described in the text) is shown on the $Y$ axis. The mtDNA content in peripheral blood of stage I breast cancers is significant lower than in the other stages according the One-way ANOVA on the ranks (*P = 0.018). Horizontal lines: group medians; boxes: $25--75 \%$ quartiles,, range, peak and minimum. ment [9]. In addition, previous studies have suggested the potential use of mtDNA as biomarker for the early detection of cancer [25]. Low mtDNA content was identified in tumors specimens of breast cancer at an early stage, suggesting that it might be essential in early progression of breast cancer, most probably by impairing the oxidative phosphorylation or mitochondrial bioenergetics [8]. Jiang et al. showed a significantly increased mtDNA content in the saliva with advanced stage [15]. The change of mtDNA may therefore be important for cancer initiation and progression [14]. However, few studies have addressed the deletion and mutation of mtDNA in tumor

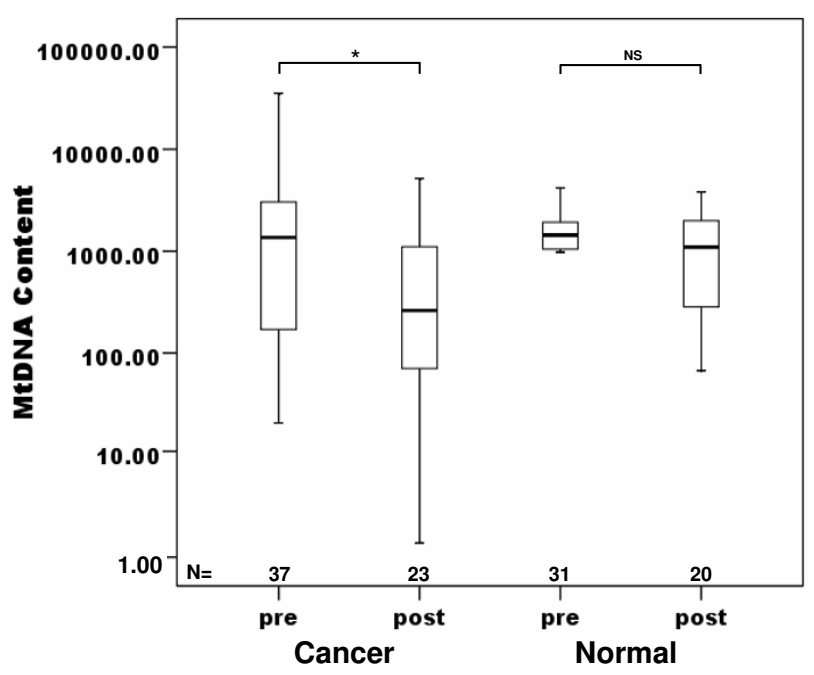

Figure 4

Box plot analysis illustrating levels of mtDNA in peripheral blood of breast cancer patients according the menopausal status. The quantitative mtDNA content is shown on the $Y$ axis. The mtDNA content in peripheral blood of postmenopausal patients is significant lower than premenopausal patients according the Mann-Whitney $U$ Test ( $* P=0.024$, NS: not significant); Horizontal lines: group medians; boxes: $25--75 \%$ quartiles, range, peak and minimum. 
tissues and blood of patients with breast cancer and the published results were inconsistent. Recent studies did not detect mtDNA mutations and deletions in the blood of women with breast cancer, implying that the mtDNA deletion and mutation play a minor role in breast carcinogenesis [26-28]. Furthermore, no previous data exist regarding the content of mtDNA in peripheral blood of breast cancer patients. In our study, we used MTATP 8 gene, a mitochondrial DNA encoded ATPase, to analyze the quantities of mtDNA in peripheral blood. We show that mtDNA content in whole blood from breast cancer patients significantly decreased in stage I breast cancer samples as compared with more advanced stages. This suggests that breast cancer cells depleted a high amount of mtDNA in the circulating system. mtDNA depletion could affect progression and metastasis of cancer cells by preventing apoptosis and generating cancer-related proteins [22]. The high frequency of mtDNA alterations in cancer and their presence in the stages I disease could possibly be exploited as clinical markers for early cancer detection [29]. Interestingly, Barrientos et al. reported that an increase in mtDNA content might be a compensatory response for decline in respiratory function [30]. So, that was why our results showed that mtDNA content firstly decreased at stage I and subsequently increased by the normal levels at stage II and stage III-IV.

A previous quantitative analysis suggested that the mtDNA content did not change with age of patients [31]. Similarly, our results displayed no significant difference between the decreased mtDNA content and age of patients. However, a recent report showed that the reduced copy number in mtDNA was more frequent in patients older than 50 years of age [8]. The relationship, therefore, between mtDNA content and patient's age needs further investigation. mtDNA circulates in peripheral blood not only in a cell-free form but also in a particle-associated form [32]. Mehra et al. showed that circulating concentrations of genomic DNA and mtDNA were not correlated with each other in plasma, probably due to the different compartmentalization and degradability of mtDNA and nDNA in cancers [33]. In line to this report, our results revealed no significant association between mtDNA content and nDNA content in peripheral blood from breast cancer patients.

The association between mtDNA content in peripheral blood and patients' age or clinical-pathological parameters was determined. No correlations between mtDNA content in peripheral blood and those parameters of breast cancer could be observed. Yu et al. have previously shown reduced mtDNA content to have a significant correlation with ER or PR status [8,19]. Endocrine treatment is essential for premenopausal as well as postmenopausal breast cancer patients [34]. Several studies showed that mitochondria respiration varies during the menstrual cycle and is correlated with pregnancy[35,36]. In our study, reduced mtDNA content inclined to have a significant correlation with menopausal status of breast cancer patients. However, whether reduced mtDNA in peripheral blood of breast cancer patients could potentially affect the outcome of endocrine treatment of breast cancer remains unknown.

\section{Conclusion}

Our data suggest that the decrease of mtDNA content in peripheral blood of patients with breast cancer may have diagnostic and prognostic value. Decreased mtDNA content is associated with the menopausal status of patients and TNM stage of cancers. The use of mtDNA may have diagnostic and prognostic value and further studies are required to validate it as a potential biomarker for early detection of breast cancer.

\section{Competing interests}

The authors declare that they have no competing interests.

\section{Authors' contributions}

HXA, XYZ, WH, RE-C and CXD conceived of the study and participated in its design and coordination. PX participated in DNA extraction and real time PCR experiment, carried out the relevant statistical analysis, and drafted the manuscript. RR, PX and CK collected clinical data. HXA and EF helped to draft the manuscript. All authors read and approved the final manuscript.

\section{Acknowledgements}

We would like to thank Mrs. Vivian Kiefer and Mrs. Nicole Chiodetti for their expert technical help and continued support. We are very grateful to Dr. Lei Meng and Dr. Hua Xu for collecting samples. We are thankful to Mrs. Regan Geissmann for proofreading the text.

\section{References}

I. Warburg O: the metabolism of tumors. London Constable Co Ltd I93I.

2. Warburg O: On the origin of cancer cells. Science 1956, I 23:309-314.

3. Denko NC: Hypoxia, HIFI and glucose metabolism in the solid tumour. Nat Rev Cancer 2008, 8:705-7I3.

4. Zeviani M, Antozzi C: Mitochondrial disorders. Mol Hum Reprod 1997, 3:|33-|48.

5. Mambo E, Chatterjee A, Xing M, Tallini G, Haugen BR, Yeung SC, Sukumar S, Sidransky D: Tumor-specific changes in mtDNA content in human cancer. Int J Cancer 2005, I I 6:920-924.

6. Selvanayagam P, Rajaraman S: Detection of mitochondrial genome depletion by a novel cDNA in renal cell carcinoma. Lab Invest 1996, 74:592-599.

7. Wu CW, Yin PH, Hung WY, Li AF, Li SH, Chi CW, Wei YH, Lee HC: Mitochondrial DNA mutations and mitochondrial DNA depletion in gastric cancer. Genes Chromosomes Cancer 2005, 44:19-28.

8. Yu M, Zhou Y, Shi Y, Ning L, Yang Y, Wei X, Zhang N, Hao X, Niu R Reduced mitochondrial DNA copy number is correlated with tumor progression and prognosis in Chinese breast cancer patients. IUBMB Life 2007, 59:450-457.

9. Jiang WW, Rosenbaum E, Mambo E, Zahurak M, Masayesva B, Carvalho AL, Zhou S, Westra WH, Alberg AJ, Sidransky D, Koch W, Califano JA: Decreased mitochondrial DNA content in 
posttreatment salivary rinses from head and neck cancer patients. Clin Cancer Res 2006, I 2: I564-I569.

10. Wang Y, Liu VW, Xue WC, Cheung AN, Ngan HY: Association of decreased mitochondrial DNA content with ovarian cancer progression. Br J Cancer 2006, 95: I087-I091.

II. Lee HC, Li SH, Lin JC, Wu CC, Yeh DC, Wei YH: Somatic mutations in the D-loop and decrease in the copy number of mitochondrial DNA in human hepatocellular carcinoma. Mutat Res 2004, 547:7I-78.

12. Yin PH, Lee HC, Chau GY, Wu YT, Li SH, Lui WY, Wei YH, Liu TY, Chi CW: Alteration of the copy number and deletion of mitochondrial DNA in human hepatocellular carcinoma. $\mathrm{Br}$ J Cancer 2004, 90:2390-2396.

13. Morten KJ, Ashley N, Wijburg F, Hadzic N, Parr J, Jayawant S, Adams S, Bindoff L, Bakker HD, Mieli-Vergani G, Zeviani M, Poulton J: Liver mtDNA content increases during development: a comparison of methods and the importance of age- and tissue-specific controls for the diagnosis of mtDNA depletion. Mitochondrion 2007, 7:386-395.

14. Mizumachi T, Muskhelishvili L, Naito A, Furusawa J, Fan CY, Siegel ER, Kadlubar FF, Kumar U, Higuchi M: Increased distributional variance of mitochondrial DNA content associated with prostate cancer cells as compared with normal prostate cells. Prostate 2008, 68:408-417.

15. Jiang WW, Masayesva B, Zahurak M, Carvalho AL, Rosenbaum E, Mambo E, Zhou S, Minhas K, Benoit N, Westra WH, Alberg A, Sidransky $D$, Koch $W$, Califano J: Increased mitochondrial DNA content in saliva associated with head and neck cancer. Clin Cancer Res 2005, I I :2486-249I.

16. Wang Y, Liu VW, Xue WC, Tsang PC, Cheung AN, Ngan HY: The increase of mitochondrial DNA content in endometrial adenocarcinoma cells: a quantitative study using laser-captured microdissected tissues. Gynecol Oncol 2005, 98: I04-I I0.

17. Jones JB, Song Jempen PM, Parmigiani G, Hruban RH, Kern SE: Detection of mitochondrial DNA mutations in pancreatic cancer offers a "mass"-ive advantage over detection of nuclear DNA mutations. Cancer Res 200 I, 6 I: | 299- I 304.

18. Fliss MS, Usadel H, Caballero OL, Wu L, Buta MR, Eleff SM, Jen J, Sidransky D: Facile detection of mitochondrial DNA mutations in tumors and bodily fluids. Science 2000, 287:2017-2019.

19. Fan AX-C, R R, Haghighi MM, Kohler C, Xia P, Hahn S, Holzgreve W, Zhong $X Y$ : Mitochondrial DNA content in paired normal and cancerous breast tissue samples from patients with breast cancer. J Cancer Res Clin Oncol 2008 in press.

20. Poe BG, Navratil M, Arriaga EA: Absolute quantitation of a heteroplasmic mitochondrial DNA deletion using a multiplex three-primer real-time PCR assay. Anal Biochem 2007, 362:193-200.

21. Kochl S, Niederstatter H, Parson W: DNA extraction and quantitation of forensic samples using the phenol-chloroform method and real-time PCR. Methods Mol Biol 2005, 297:13-30.

22. Higuchi M: Regulation of mitochondrial DNA content and cancer. Mitochondrion 2007, 7:53-57.

23. Chan DC: Mitochondrial fusion and fission in mammals. Annu Rev Cell Dev Biol 2006, 22:79-99.

24. Gatenby RA, Gillies RJ: Why do cancers have high aerobic glycolysis? Nat Rev Cancer 2004, 4:891-899.

25. Modica-Napolitano JS, Kulawiec M, Singh KK: Mitochondria and human cancer. Curr Mol Med 2007, 7:|2|-|3|

26. Losanoff JE, Z W, Qin W, Mannello F, Sauter ER: Can mitochondrial DNA mutations in circulating white blood cells and serum be used to detect breast cancer? Breast 2008, I 7:540-542.

27. Ye C, Shu XO, Wen W, Pierce L, Courtney R, Gao YT, Zheng W, Cai Q: Quantitative analysis of mitochondrial DNA 4977-bp deletion in sporadic breast cancer and benign breast diseases. Breast Cancer Res Treat 2008, I 08:427-434.

28. Tseng LM, Yin PH, Chi CW, Hsu CY, Wu CW, Lee LM, Wei YH, Lee HC: Mitochondrial DNA mutations and mitochondrial DNA depletion in breast cancer. Genes Chromosomes Cancer 2006, 45:629-638.

29. Modica-Napolitano JS, Singh KK: Mitochondria as targets for detection and treatment of cancer. Expert Rev Mol Med 2002, 4:1-19.

30. Barrientos A, Casademont J, Cardellach F, Estivill X, Urbano-Marquez A, Nunes V: Reduced steady-state levels of mitochondrial
RNA and increased mitochondrial DNA amount in human brain with aging. Brain Res Mol Brain Res 1997, 52:284-289.

31. Miller FJ, Rosenfeldt FL, Zhang C, Linnane AW, Nagley P: Precise determination of mitochondrial DNA copy number in human skeletal and cardiac muscle by a PCR-based assay: lack of change of copy number with age. Nucleic Acids Res 2003 , 3I:e6I.

32. Chiu RW, Chan LY, Lam NY, Tsui NB, Ng EK, Rainer TH, Lo YM: Quantitative analysis of circulating mitochondrial DNA in plasma. Clin Chem 2003, 49:719-726.

33. Mehra N, Penning M, Maas J, van Daal N, Giles RH, Voest EE: Circulating mitochondrial nucleic acids have prognostic value for survival in patients with advanced prostate cancer. Clin Cancer Res 2007, 13:421-426.

34. Lin NU, Winer EP: Advances in adjuvant endocrine therapy for postmenopausal women. J Clin Oncol 2008, 26:798-805.

35. Buffenstein R, Poppitt SD, McDevitt RM, Prentice AM: Food intake and the menstrual cycle: a retrospective analysis, with implications for appetite research. Physiol Behav 1995, 58:1067-I077.

36. Webb P: 24-hour energy expenditure and the menstrual cycle. Am J Clin Nutr 1986, 44:614-619.

\section{Pre-publication history}

The pre-publication history for this paper can be accessed here:

http://www.biomedcentral.com/1471-2407/9/454/pre pub
Publish with Biomed Central and every scientist can read your work free of charge

"BioMed Central will be the most significant development for disseminating the results of biomedical research in our lifetime. "

Sir Paul Nurse, Cancer Research UK

Your research papers will be:

- available free of charge to the entire biomedical community

- peer reviewed and published immediately upon acceptance

- cited in PubMed and archived on PubMed Central

- yours - you keep the copyright
BioMedcentral 